\section{Postproduction Performance of 'Gloria' Azalea in Response to Flower Maturity and Simulated Transport}

\author{
Lori A. Black, Terril A. Nell, and James E. Barrett \\ Environmental Horticulture Department, University of Florida, \\ Gainesville, FL 32611
}

Additional index words. longevity, stage of development, postharvest, holding, Rhododendron sp.

\begin{abstract}
Dormant-budded 'Gloria' azaleas (Rhododendron sp.) at various maturity levels (one, eight, or 32 individual open flowers) were moved from the greenhouse to postproduction rooms. Postproduction rooms were maintained at $21 \pm 1 \mathrm{C}$, relative humidity $50 \% \pm 5 \%$, and 12 hours of daily irradiance at $12 \mu \mathrm{mol} \cdot \mathrm{s}^{-1} \cdot \mathrm{m}^{-2}$ from coolwhite fluorescent lamps to simulate home conditions. Using predetermined categories, the number of tight, showing-color, candle, and open-flower inflorescences were recorded. After 2 weeks postproduction, plants chosen at the start of postproduction with eight or 32 individual open flowers had the best flowering uniformity and flower color. In a second experiment, azaleas with one, eight, or 32 individual open flowers were placed into simulated transport for 4 days at $16 \pm 1 \mathrm{C}$. Plants with one individual open flower had greatest longevity, but those with eight open flowers had the best overall postproduction performance. In a final experiment, azaleas at similar maturity levels were placed in simulated transport at 5, 16, or 27C for 2,4 , or 6 days. After 2 weeks postprodudion, there was no difference due to simulated-transport temperature or duration on flowering performance or flower color. Longevity was good for plants held 2,4 , or 6 days at $5 \mathrm{C}$ and for plants held for 2 days at 16 or $27 \mathrm{C}$.
\end{abstract}

The optimum maturity level for marketing florist azaleas has not yet been evaluated on the basis of postproduction performance. Maturity level has been shown to be a factor in the postproduction longevity of potted chrysanthemums (Walter, 1974; Wesenberg and Beck, 1964). The former found that longevity of mature potted chrysanthemum flowers exceeded that of very immature flowers by 1 to 3 days. Maturity level has also been shown to be important in the postproduction longevity of stored Easter lilies (Staby and Erwin, 1977). The importance of maturity level in postproduction performance and longevity has been attributed to the ability of flower buds to develop properly in the low irradiance levels found in interior environments (Wesenberg and Beck, 1964).

Temperature and duration of transport are critical to the maintenance of high-quality plants in the postproduction environment. Sterling and Molenaar (1986) conducted a study using 20 species of container-grown plants in simulated transport with varying temperatures and durations. They found that flowering plants were generally more sensitive to transport temperature than foliage plants and required lower temperatures during transport to avoid leaf and bud yellow-

Received for publication 12 Feb. 1990. Florida Agr. J. Ser. no. R-00455. We are grateful to American Floral Endowment for support of this project and to Yoder Brothers for the plants used in this study. Also, we are indebted to Jill L. Johnson for the biological illustration. The cost of publishing this paper was defrayed in part by the paymentt of page charges. Under postal regulations, this paper therefore must be hereby marked advertisement soley to indicate this fact. formance of 'Gloria' azalea.

Cultural practices. Dormant-budded
'Gloria' azaleas with an 18- to 23-cm crown diameter in $15-\mathrm{cm}$ pots (1.6 liters) were obtained from a commercial grower (Yoder Brothers, Alva, Fla.) and held for 6 weeks at $2 \pm 0.5 \mathrm{C}$ with $15 \mu \mathrm{mol} \cdot \mathrm{s}^{-1} \cdot \mathrm{m}^{-2}$ of irradiance from. 40-W cool-white fluorescent lamps. After cold treatment, plants were placed into a fiberglass greenhouse with fanand-pad cooling at temperatures ranging from a maximum day of $35 \mathrm{C}$ to a minimum night of $24 \mathrm{C}$. Plants were watered daily with tap water, but no fertilizer was applied.

Experimental procedures. Postproduction evaluations were conducted in three rooms that provided $21 \pm 1 \mathrm{C}, 50 \% \pm 5 \%$ relative humidity (RH), and $12 \mu \mathrm{mol} \cdot \mathrm{s}^{-1} \cdot \mathrm{m}^{-2}$ of irradiance, $12 \mathrm{~h}$ daily, from cool-white fluorescent lamps to simulate consumer home conditions, each room being a replication. For postproduction evaluations, inflorescences were categorized into four development categories: 1) tight, inflorescence buds with no flower color showing; 2) showingcolor, inflorescence buds exhibiting no more than $2.5 \mathrm{~cm}$ of flower color; 3) candle, in florescence buds with $<2.5 \mathrm{~cm}$ of flower color showing; and 4) open-flower, flowers with a diameter of $3 \mathrm{~cm}$ or greater (Fig. 1). Inflorescences contained an average of three flowers each. In all experiments, the number of tight, showing-color, candle, and openflower inflorescences were determined at the start of postproduction and after 2 weeks postproduction. All treatments were applied after flower buds had been initiated; therefore, the sum of the number of tight, showingcolor, candle, and open-flower inflores-

Table 1. The effect of maturity level on postproduction longevity of 'Gloria' azalea with and without a simulated transport treatment.

\begin{tabular}{lcc}
\hline & \multicolumn{2}{c}{ Longevity (days) } \\
\cline { 2 - 3 } $\begin{array}{l}\text { Maturity } \\
\text { level }^{z}\end{array}$ & $\begin{array}{c}\text { No simulated } \\
\text { transport }\end{array}$ & $\begin{array}{c}\text { Simulated } \\
\text { transporty }\end{array}$ \\
\hline 1 & 30 & 25 \\
8 & 26 & 23 \\
32 & 25 & 21 \\
HSD $_{0.05}$ & 2 & 2 \\
HSD $_{0.01}$ & 3 & 2 \\
\hline
\end{tabular}

${ }^{2}$ Number of individual open flowers at the start of postproduction or simulated transport.

"Plants were placed in closed boxes for 4 days at $16 \pm 1 \mathrm{C}$

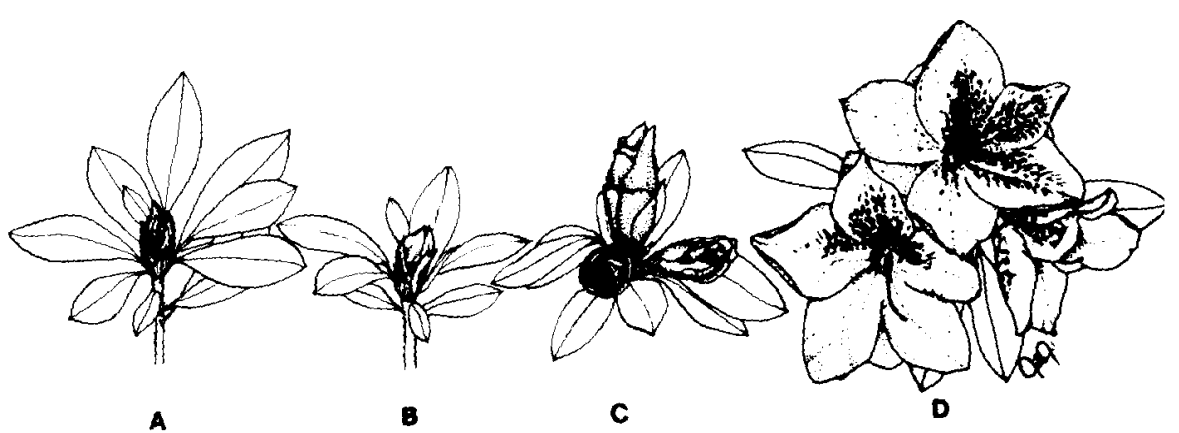

Fig. 1. Four inflorescence categories chosen to evaluate postproduction performance of 'Gloria' azalea (A) Tight, inflorescence buds with no flower color showing (B) showing-color, inflorescence buds exhibiting no more than $2.5 \mathrm{~cm}$ of flower color; (C) candle, inflorescence buds with $<2.5$ or flower color; and (D) open-flower, flowers with a diameter of $3 \mathrm{~cm}$ or greater. 


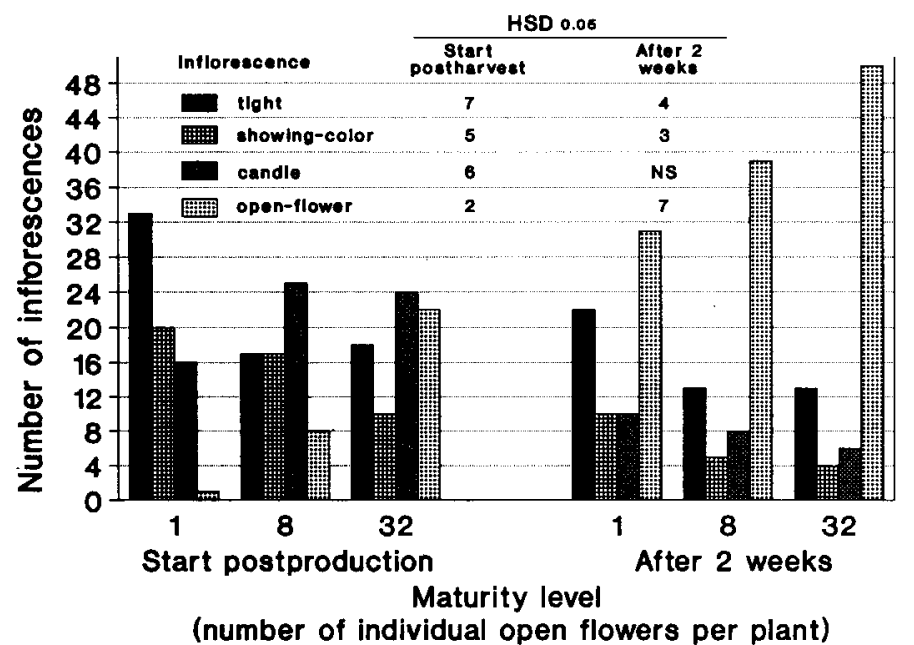

Fig. 2. Effect of maturity level (based on the number of individual open flowers) on the number of tight, showing-color, candle, and open-flower inflorescences on 'Gloria' azalea at the start and after 2 weeks postproduction at $21 \mathrm{C}$. Plants did not receive a simulated transport treatment.

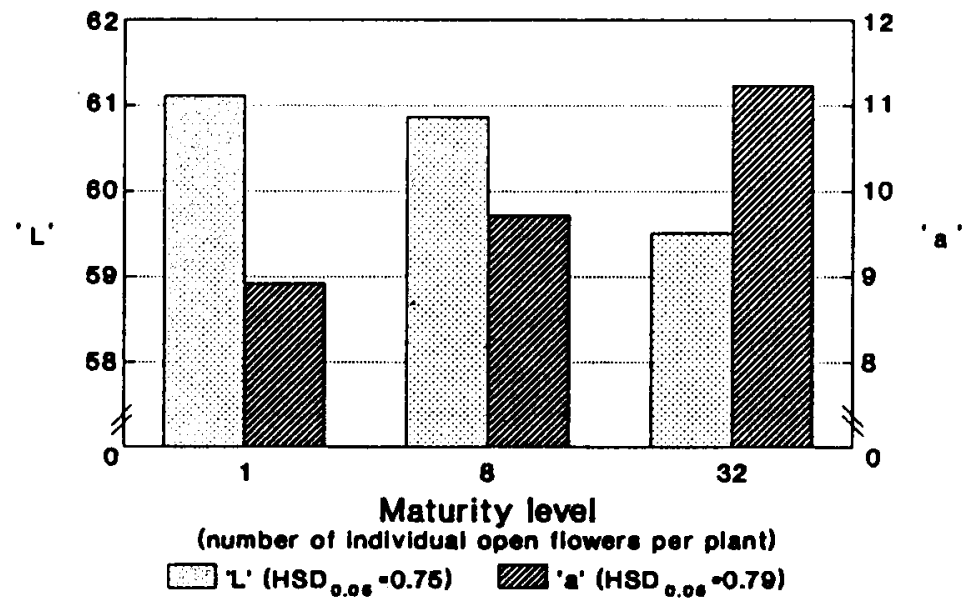

Fig. 3. Effect of maturity level (based on the number of individual open flowers) on Hunter ' $\mathrm{L}$ ' (O = black, $100=$ white) and ' $a$ ' (positive $=$ red, negative $=$ green) values for 'Gloria' azalea flower petals after 2 weeks postproduction at 21C. Plants did not receive a simulated transport treatment.

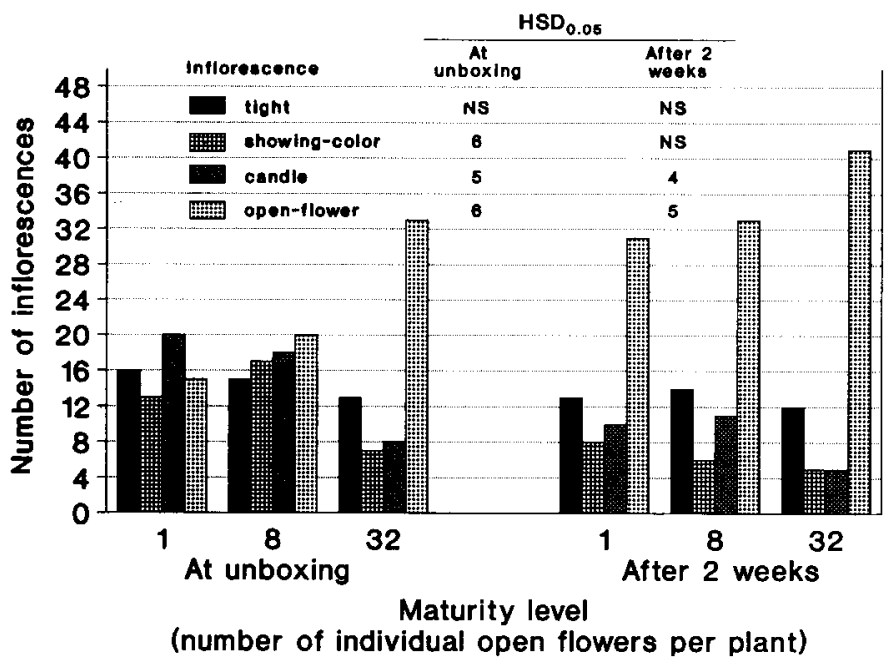

Fig. 4. Effect of maturity level (based on the number of individual open flowers) at time of simulated transport (plants were placed into closed boxes for 4 days at $16 \pm 1 \mathrm{C}$ ) on the number of tight, showing-color, candle, and open-flower inflorescences on 'Gloria' azaleas at unboxing and after 2 weeks postproduction at $21 \mathrm{C}$.

cences (total number of inflorescences) was not affected by treatments. No inflorescence or flower bud abscission was observed on plants of any treatment. Postproduction lon- gevity was determined as the number of days from placement in postproduction to when $90 \%$ to $95 \%$ of all flowers showed signs of necrosis.

Maturity level was based on the number of individual open flowers. The industry standard for stage of marketability is eight individual open flowers. Plants with one individual open flower and those with 32 individual open flowers were used to achieve a maturity level below and above that used by commercial growers. The number of inflorescences were counted as a means of determining flowering uniformity and overall plant development. Tight and showingcolor inflorescences are seen as one bud (Fig. $1 \mathrm{~A}$ and $\mathrm{B})$. When inflorescences develop to the candle and open-flower stage, each individual flower is visible (Fig. $1 \mathrm{C}$ and D). Therefore, to be consistent in counting each category chosen, the number in each inflorescence type was recorded.

After 2 weeks postproduction, flower color of the adaxial petal surface of four flowers per experimental unit, devoid of red spots, was determined with a HunterLAB colorquest sphere spectrocolorimeter (Hunter Associates Laboratory, Reston, Va.) using ' $L$ ' ( 0 = black, $100=$ white) and 'a' (red toward positive and green toward negative) modes. The instrument was calibrated according to manufacturers instructions using standard white $(X=81.70, Y=86.53, Z=93.98)$ and gray $(\mathrm{X}=51.37, \mathrm{Y}=54.64, \mathrm{Z}=$ 59.20) reference plates. A 'Gloria' flower petal with an intense pink color would have a low ' $L$ ' value and a high positive 'a' value. Data were tested by analysis of variance, $\mathrm{Tu}$ key's honestly significant difference test (HSD), and regression analysis.

Maturity level Expt. 1). Plants were removed from the greenhouse at three maturity levels: one, eight, or 32 individual open flowers. Plants were placed directly into postproduction rooms, based on their maturity level, for postproduction evaluation. We used a randomized complete block with five plants per experimental unit and three replications. The number of each inflorescence type was determined at the start of postproduction and after 2 weeks. One petal from each of four flowers per plant was used, a total of 60 petals per treatment, for color determination.

Maturity level in simulated transport (Expt. 2). Plants were removed from the greenhouse at maturity levels of one, eight, or 32 individual open flowers and held in closed boxes (without sleeves) for 4 days at $16 \pm$ $1 \mathrm{C}$ to simulate transport. Afterwards, plants were placed into postproduction rooms. The design was a randomized complete block with four plants per experimental unit and three replications. The number of each inflorescence type was determined at unboxing and after 2 weeks postproduction. One petal from each of four flowers per plant was used, a total of 48 petals per treatment, for color determination.

Simulated-transport temperature and $d u$ ration (Expt. 3). A $3 \times 3$ factorial experiment was conducted with simulated transport 


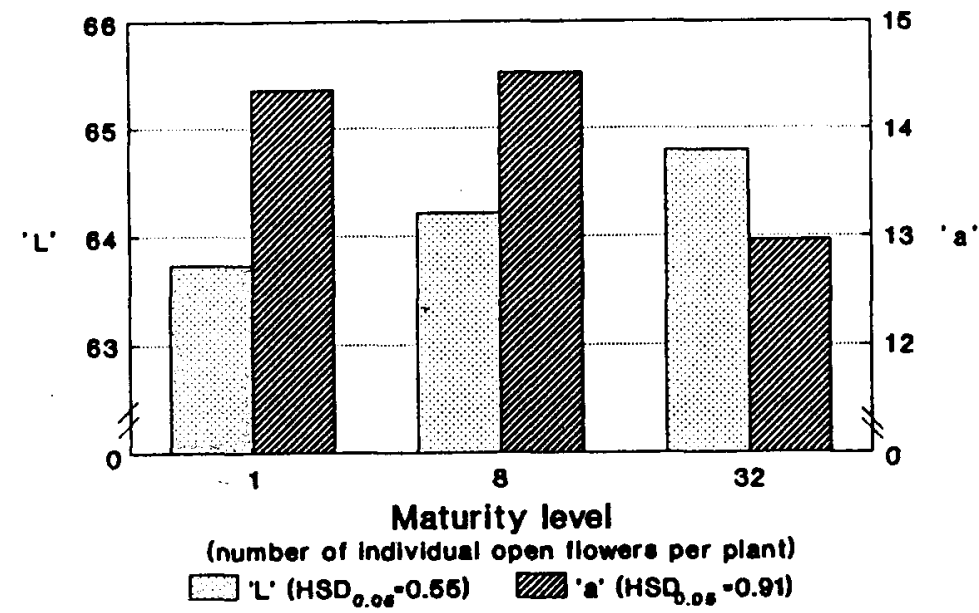

Fig. 5. Effect of maturity level (based on the number of individual open flowers) at time of simulated transport (plants were placed into closed boxes for 4 days at $16 \pm 1 \mathrm{C})$ on Hunter ' $L$ ' $(100=$ white, $0=$ black) and ' $a$ ' (positive $=$ red, negative $=$ green $)$ values of 'Gloria' azalea flower petals after 2 weeks postproduction at $21 \mathrm{C}$

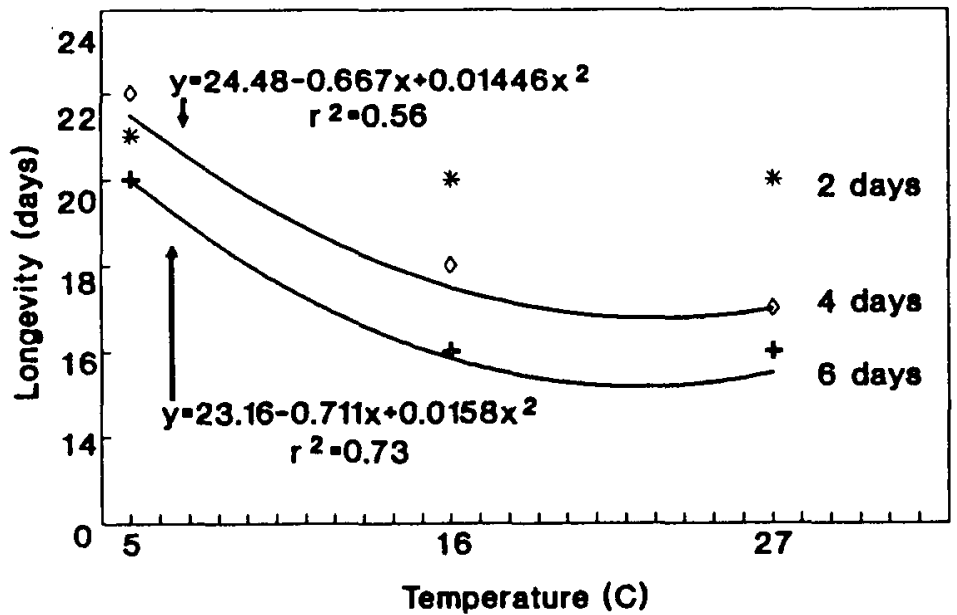

Fig. 6. Effect of simulated-transport temperature (5, 16, and $27 \pm 1 \mathrm{C})$ and duration $(2,4$, and 6 days) on the postproduction longevity of 'Gloria' azalea. Interaction significant at $P=0.01$. Regression analysis of plants transported for 2 days was nonsignificant. Points are means of six plants at each level. Regression analysis used values for each plant.

at $5 \pm 1,16 \pm 1$, or $27 \pm 1 \mathrm{C}$ for 2,4 , or 6 days. The experiment was a randomized complete block design with three replications and two plants per experimental unit. Plants were placed under simulated transport conditions when eight to 10 individual flowers were open. Transport conditions and the number of each inflorescence type were the same as described in Expt. 2. One petal from each of four flowers per plant was used, a total of 24 petals per treatment, for color determination.

Effect of maturity level (Expt. 1). At the start of the postproduction period, plants with one individual open flower had more tight inflorescences and fewer candle and openflower inflorescences than those with eight or 32 individual open flowers (Fig. 2). After 2 weeks postproduction, plants that had been moved with eight or 32 individual open flowers had the most open-flower inflorescences and the fewest of the others. These plants had a uniform flowering appearance. Plants moved with one individual open flower had the fewest open-flower inflorescences and the most tight inflorescences after 2 weeks in the interior, and they appeared as nonuniform flowering azaleas.

After 2 weeks in postproduction, the ' $\mathrm{a}$ ' value (flower redness) was higher and ' $L$ ' value (lightness) was lower for plants moved into postproduction with 32 individual open flowers than those moved into postproduction with one or eight open (Fig. 3). The more intense flower color, observed in plants with 32 individual open flowers, presumably is an effect of extended production time in the high-irradiance greenhouse. Production time, from the start of the greenhouse phase until the start of postproduction, was 26, 30, and 33 days for the one, eight, and 32 individual open flowers maturity level, respectively $\left(P=0.0002, \mathrm{HSD}_{0.05}=2\right)$.

Plants moved into postproduction with one individual open flower lasted 4 days longer than those moved with eight and 5 days longer than those moved with 32 individual open flowers (Table 1).

These results demonstrate that the more mature plants, placed into low-irradiance conditions, have a greater floral display and a more intense flower color during postproduction. However, longevity decreased as maturity level increased from one to 32 individual open flowers. Overall, plants with a maturity level of eight individual open flowers appeared to be uniformly flowering and had an intense flower color after 2 weeks postproduction and an average postproduction longevity of 26 days.

Effect of maturity level in simulated transport (Expt 2). At unboxing, plants held in simulated transport in closed boxes for 4 days at $16 \pm 1 \mathrm{C}$ with 32 individual open flowers had the most open-flower inflorescences and the fewest candle and showing-color inflorescences (Fig. 4). Plants placed in simulated transport with one or eight individual open flowers had more showing-color and candle inflorescences at unboxing than plants transported with 32 individual open flowers. The number of tight inflorescences at unboxing was not affected by the maturity level when plants were placed into simulated transport.

After 2 weeks postproduction, plants placed in simulated transport with 32 individual open flowers had the most open-flower inflorescences and the fewest candle inflorescences (Fig. 4). The number of tight and showingcolor inflorescences was similar after 2 weeks in the interior for all maturity levels evaluated. The number of open-flower inflorescences after 2 weeks postproduction was similar for plants with one or eight individual open flowers initially.

Flower color intensity was higher (high ' $a$ ' value and low ' $L$ ' value) after 2 weeks in the interior for plants with one or eight individual open flowers than for those with 32 (Fig. 5). This observation of a low flower color intensity for those with 32 individual open flowers is opposite of that observed when plants did not receive a simulated transport treatment. These data suggest that simulated transport has a detrimental effect on the flower color of more-mature plants.

Longevity was greatest for plants with one open flower at initiation of simulated transport (Table 1). These results are similar to those discussed in Expt. 1. Once again, even with a simulated transport treatment, plants with a maturity level of eight individual open flowers had the best overall qualities after 2 weeks postproduction.

Effect of simulated-transport temperature and duration (Expt. 3). After 2 weeks postproduction, the number of tight, showingcolor, candle, and open-flower inflorescences and flower color intensity were similar for all simulated-transport temperature or duration combinations (data not shown). From these data we can conclude that the flowering appearance is not affected by transport temperatures between 5 and $27 \mathrm{C}$ or durations from 2 to 6 days.

There was a significant interaction between simulated-transport temperature and duration for postproduction longevity. Longevity was greatest for plants placed at 5C regardless of duration and for those held for 2 days at 16 or $27 \mathrm{C}$ (Fig. 6). These data are 
in agreement with the optimum transport temperature and duration found for Rhododendron indica (Sterling and Molenaar, 1986). When plants were placed in simulated transport for 4 or 6 days, longevity decreased dramatically at 16 or $27 \mathrm{C}$.

Optimum transport temperatures and durations for 'Gloria' azaleas, based on present results, are $5 \mathrm{C}$ for up to 6 days or 2 days at 16 or $27 \mathrm{C}$. Further research is needed to test the upper and lower limits of transport temperature and duration.

\section{Literature Cited}

Conover, C.A. and R.T. Poole. 1984. Influence of temperature and duration on simulated ship- ping of small potted foliage plants. Proc. Fla State Hort. Soc. 97:280-282.

Hoyer, L. 1986. Silver thiosulfate can to some extent prevent leaf, bud and flower drop in $\mathrm{Hi}$ biscus-rosa sinensis caused by ethylene and darkness. Acta Hort. 181:147-153.

Nell, T.A. and J.E. Barrett. 1984. Effect of simulated shipping temperature and duration on prefinished flowering hibiscus. Proc. Fla. State Hort. Soc. 97:278-279.

Rystedt, J. 1982a. Effects of high and low temperatures on the subsequent keeping quality of Hibiscus rosa-sinensis and Begonia 'Nixe'. Tidsskr. Planteavl 86:31-36.

Rystedt, J. 1982b. Effects of dark storage on the subsequent keeping quality of Hibiscus rosasinensis and Begonia 'Nixe'. Tidsskr. Planteavl 86:37-46.
Staby, G.L. and T.D. Erwin. 1977. The storage of Easter lilies. Florists' Rev. 161(4162):38.

Sterling, B. and P. Molenaar. 1986. The influence of time and temperature during simulated shipment on the quality of pot plants. Acta Hort. 181:429-438.

Thaxton, D. R., J.W. Kelly, and J.J. Frett. 1988. Control of Hibiscus rosa-sinensis L. bud abscission during shipping. Scientia Hort. 34: 131137.

Walter, V.R. 1974. Studies of the keeping quality of potted chrysanthemums as affected by differential degrees of flower development. Ohio Florists' Assn. Bul. 539:7-9.

Wesenberg, B.G. and G.E. Beck. 1964. Influence of production environment and other factors on the longevity of potted chrysanthemum flowers (Chrysanthemum morifolium Ramat.). Amer. Soc. Hort. Sci. 85:584-590. 